\title{
Diagnosis and Clinical Treatment of Transmissible Venereal Tumor in Canines
}

\author{
C. K. Lakde*, A. A. Bind and S. K. Sahatpure \\ Department of Animal Reproduction Gynaecology and Obstetrics \\ Nagpur Veterinary College, \\ Maharashtra Animal \& Fishery Sciences University, Seminary Hills, \\ Nagpur - 440006 (Maharashtra), India \\ *Corresponding author
}

Keywords

Autohaemotherapy, Dog, TVT,

Vincristine sulphate

Article Info

Accepted:

04 August 2020

Available Online:

10 September 2020

\section{A B S T R A C T}

A total of 105 cases of canine from both the sexes in the period in the period of one year were suspected for transmissible venereal tumor in Teaching Veterinary Clinical Complex. Nagpur. From total 105 dogs 62 male and 43 females. Male and female has complaint of prepucial and vaginal bleeding respectively. Tumor impression smear was taken while in anterior type of tumor diagnosed by vaginal cytology. Result concluded that smear picture show round to slightly polyhedral cells TVT cells. Out of total 95 cases were treated with Inj. Vincristine @ $0.025 \mathrm{mg} / \mathrm{kg}$ slow IV in DNS and 10 cases treated with autohaemotherapy @ $10 \mathrm{ml}$ whole blood IM for once in week and continue for upto its complete regression. Also from recovery point of view we noted that, it was faster in VS than AHT. But side effect observed only in VS treated dogs. From the study we concluded that AHT will be an alternate option for treatment of TVT who shows the excessive side effects of VS.

\section{Introduction}

Transmissible venereal tumor is a tumor of the canines that mainly affects the external genitalia because of its mainly sexual transmitted nature. It mainly transmitted from animal to animal through sexual intercourse with affected animal and may also be passed on as the dog bites, sniffs or licks the tumor affected areas (Dass et al., 1989). CTVT appears as a cauliflower like growth on external genitalia and may sometimes show discharge and bleeding from vaginal canal. In bitches it was found full of granulomatous tissue with growth on uteri. Tumor is mostly seen in sexually active and adult dogs. Female are more susceptible than male with more concentration of free roaming dogs with 
uncontrolled reproduction (Gandotra et al.1993). In bitches, it affects the vulva, vagina and os uteri. In immunosuppressed bitches, the tumor is spread in cancerous manner.

Treatment of affected TVT dogs is beneficial than surgery. Vincristine sulfate has long been demonstrated to be effective as a single chemotherapeutic agent in the management of CTVT.

Major advantages of treating bitches for TVT with Vincristine sulphate are its high cure rate, fast recovery, high cure rate and usefulness in metastasis. But it has some disadvantages like inappetance or partial inappetance, vomition, diarhhoea, neutropenia and alopecia in some dogs. Autohaemotherapy in TVT cases has been successfully studied in experimental studies but its efficiency not widely evaluated clinically.

\section{Materials and Methods}

In Teaching Veterinary Clinical Complex of Nagpur Veterinary College total 10431 adult dogs were presented with overall problems having age group from about 1 year old to 14 years of age. A total of 105 cases were reported that diagnosed as venereal granuloma. Out of these cases diagnosed for TVT, 62 male (8 GSD, 6 Labrador, 1 Pug and 47 Non Descript) and 43 were females (12 GSD, 6 Labrador, 1 Pug and 24 Non Descript). From total 105 affected dogs 95 case were treated with vincristine sulphate @ $0.025 \mathrm{mg} / \mathrm{kg}$ BW by slow intravenous route in DNS fluid at weekly interval for five consecutive weeks and 10 cases by autohaemotherapy $(10 \mathrm{ml}$ whole blood Intramuscular in gluteal muscles) for seven weeks.

During the course of treatment with inj. Vincristine Sulphate side effects like vomition, anorexia and alopecia was recorded while autohaemotherapy was without any side effects. But the recovery was fast in Inj. Vincristine Sulphate (2-3 treatments) than autohaemothery (6-7 treatments).

\section{Results and Discussion}

Complaint of prepucial in dogs and vaginal bleeding in bitches recorded in cases. In male exposuring prepucial and impression smear was taken from each case. From female with posterior vaginal tumor impression smear was taken while in anterior type of tumor diagnosed by vaginal cytology. Result concluded that smear picture show round to slightly polyhedral cells TVT cells Transmissible venereal granuloma was a sexually transmitted disease either transmitted from male to female or female to male. A total 10431 dogs were studied accounting $0.01 \%$ incidence of transmissible venereal granuloma which was very less compared to observation of (Khan et al., 2009). From the 105 diagnosed cases of TVT affected animals 62 were male (8 GSD, 6 Labrador, 1 Pug and 47 Non Descript) while 43 were female (12 GSD, 6 Labrador, 1 Pug and 24 Non Descript). In present study, we observed more number of males were affected with venereal granuloma as compared to the females in non descript breeds which was in accordance with earlier recording of (Khan et al., 2009) while Kemeto and Mugera (1974) and Moulton (1990) recorded that the males and females were in equal number which was not in accordance with the present finding.

Excluding non descript dogs, the high incidence of venereal granuloma was observed in German Shephard (8 male and 12 female). The incidence of TVT in GSD was more as compared to other specific breed because it comes in osterus three times in a year and has history of mating with stray dogs due to aggressive nature and unable to control during oestrus period (Personal opinion). Also 
incidence of TVT in non descript dog is more which could be due to the fact of its uncontrolled population in around Nagpur and surrounding areas. These dogs were free roaming and were not taken care by any one. Three consecutive injections of Vincristine revealed good result but need five injections because of its reoccurrence in respect of granulomatous growth. On an average 3 injections required to complete growth disappearance. Pharmacological action behind Vincristine Sulphate was inhibiting mitosis and bonded with tubulin by preventing the formation of mitotic spindles. Therefore from the present study it can be stated that clinical cases of canine transmissible venereal tumor could be treated successfully by using chemotherapy along with Vincristine sulphate $@ 0.025 \mathrm{mg} / \mathrm{kg}$ body wt by intravenous route. Similar findings were also observed by Das et al (1989), Bal Krishnan (1997) and Khan et al., (2009). But during the study in some dogs with the use of Vincristine sulphate complications like anorexia, vomition and alopecia were noticed. Such type of complication was also observed by Gandhimathi et al., (2011). So such 10 cases ( 6 female and 4 male) of TVT were treated by autohaemotherapy $(10 \mathrm{ml}$ whole blood injected in gluteal muscles IM once per week for seven weeks) as five week treatment was not sufficient to regressed complete tumor. During the course of autohaemotheray, slowly regression of granulomatous mass observed compared to Vincristine Sulphate but having no any effects. Duration of course for autohaemotherapy was calculated to be $6-7$ doses minimum to complete regression. Similar observation was observed by Drumond et al., (2013) (Table 1).

Table.1 Breedwise distribution of TVT cases presented at TVCC, Nagpur

\begin{tabular}{|c|c|c|c|}
\hline Dog Breed & Total cases & Male cases & Female cases \\
\hline German Shephard & 20 & 8 & 12 \\
\hline Labrador & 12 & 6 & 6 \\
\hline Pug & 02 & 1 & 1 \\
\hline Non Descript & 71 & 47 & 24 \\
\hline Total & 105 & 62 & 43 \\
\hline
\end{tabular}

From the study we concluded that autohaemotherapy will be an option to treat transmissible venereal tumour cases in dog when Vincristine shows the severe side effects like vomition, alopecia, anorexia etc.

\section{References}

Bal Krishnan, K. (1997) Transmissible venereal tumor in bitches-chemotherapy with vincristine Ind. J. of Vet. Surgery 18 (2): 107.

Das, A.K, U. Das; D.K. Das and J. Sengupta (1989): Metastasis of canine transmissible of venereal sarcoma in a dog. Ind. Vet. J; 10(1): 74-75.
Gandotra, V.K., Chauhan, F. S. and Sharma, R.D. (1993) Occurrence of canine transmissible venereal tumor and evaluation of two treatments. Indian Vet. J. 70: 854-857.

Khan, L.A., Khante, G.S., Raut, B.M., Bodkhe, A.M., Chavan, M.S., Pagrut, N.S. and Bobde, S.P. (2009). Incidence of Venereal Granuloma and its Medicinal treatment in stray Dogs of Nagpur City. Vet. World, Vol.2 (1): 1314.

Kimato, B. and G.M. Mugera (1974): Transmissible venereal tumor of dog in Kenya. Bull. of animal health and prod. 22(4): 327-329. 
Moulton, J.E. (1990): Tumours of domestic animals, third revised edition; (University of California Press, Barkely \& Los Angeles) 10: 498-502.

Drumond K.O., Quessada A.M., Silva
S.M.M.S, Costa F.A.L., Silva L.S., Goncalves L.M.F. and Lopes R.R.F.B. (2008). Regressao espontanea de tumour venereo transmissivel canino. Relato de caso. PUBVET. 2(38):367.

\section{How to cite this article:}

Lakde, C.K., A.A. Bind and Sahatpure, S.K. 2020. Diagnosis and Clinical Treatment of Transmissible Venereal Tumor in Canines. Int.J.Curr.Microbiol.App.Sci. 9(09): 179-182. doi: https://doi.org/10.20546/ijcmas.2020.909.022 